DOI: http://dx.doi.org/10.17793/rdd.v4i7.823

\title{
8. A (HIPER)VULNERABILIDADE DE IVAN ILITCH
}

\author{
8. IVAN ILITCH’S (HYPER)VUNENRABILITY
}

\section{Guilherme Damasio Goulart ${ }^{1}$}

\begin{abstract}
Resumo: Este artigo apresenta uma análise da situação de (hiper)vulnerabilidade do personagem Ivan Ilitch da novela "A morte de Ivan Ilitch" de Tolstói. Levando em conta a doença do protagonista, são examinados alguns aspectos psicológicos de seu sofrimento, considerando o fato de que Ivan Ilitch sabe que sua morte é iminente. Após, tomando a novela como base, investiga-se a situação do vulnerável e do hipervulnerável no âmbito do direito privado.
\end{abstract}

Palavras-chave: A morte da Ivan Ilitch, vulnerabilidade, hipervulnerabilidade, doença, morte, direito privado.

\begin{abstract}
This paper presents an analisis of Ivan Ilych's (hyper)vulnerability situation in the novel "The Death of Ivan Ilitch". Taking into account the protagonist's illness, some psychological aspects of his suffering are examined, considering the fact that Ivan Ilitch knows that your death is iminent. After that, taking the novel as a basis, the vulnerable and hypervulnerable situation in the private law field is investigated

Keywords: The Death of Ivan Ilitch, vulnerability, hypervulnerability, illness, death, private law.
\end{abstract}

\section{Ivan Ilicth e a jornada existencial de um doente em direção à morte}

A morte de Ivan Ilitch conta a estória de um juiz de direito que, após um acidente doméstico, passa a sofrer de uma doença que o levará a morte. A obra retrata todo o sofrimento pelo qual passa um doente que sabe que vai morrer. Com grande profundidade psicológica o autor vai construindo, pouco a pouco, um cenário onde os medos do

$1 \mathrm{O}$ autor é Advogado, Mestre em Direito pela UFRGS e professor do curso de graduação em Direito no CESUCA e de pós-graduação em diversas instituições. Parte das reflexões deste artigo são provenientes dos estudos realizados no grupo de pesquisa "Vulneráveis e o Direito Privado" coordenado pelo autor no CESUCA. E-mail: guilherme@direitodatecnologia.com . 
protagonista vão se ampliando em função da morte iminente. A dor, a sensação de abandono e de impotência, "a crueldade de Deus" ${ }^{2}$ e outras sensações dolorosas e dramáticas de Ivan Ilitch são desnudadas nesta novela de Tolstói por meio de uma jornada existencial ${ }^{3}$ do personagem.

Não há dúvidas que o leitor mais atento, ao entrar no universo de Ivan Ilitch, coloca-se em seu lugar, conjecturando sobre o próprio destino e se confrontado também com a visão da própria morte, o que é um dos grandes méritos da narrativa. De igual forma, qualquer pessoa que tenha passado pelo doloroso processo de perda de alguém querido em condições análogas a de Ivan Ilitch pode, com o livro, perceber a dureza da angústia daquele que sabe que irá morrer em breve e não consegue aceitar tal circunstância.

O texto invoca e lida com o medo da morte, que pode ser visto como o "medo original", talvez o arquétipo de todos os medos ${ }^{4}$ algo inato que os humanos compartilham, até mesmo, com os animais ${ }^{5}$ em função do próprio instinto de sobrevivência ${ }^{6}$. Durante as eras a relação do humano com a morte foi sempre se alterando, bastando lembrar de uma antiguidade em que assistir pessoas sendo devoradas por leões era um divertimento tão corriqueiro quanto assistir uma partida de futebol nos tempos atuais ${ }^{7}$.

2 TOLSTÓI, Leon. A morte de Ivan Ilitch e Senhores e Servos. Rio de Janeiro: Nova Fronteira, 2013, p. 65 .

3 O existencialismo, como filosofia, aparece por volta dos anos 50 do século XX. As preocupações dessa teoria eram o estudo do si para si, os dilemas da existência, a angústia, a morte, o outro, etc, cf. PINTO, Louis. Pierre Bourdieau y la teoría del mundo social. Mexico DF: Siglo Veinteuno, 2002, p. 27

4 BAUMAN, Zygmunt. Medo Líquido. Rio de Janeiro: Jorge Zahar, 2008, p. 73.

5 ELIAS, Norbert. A solidão dos Moribundos seguido de Envelhecer e Morrer. Rio de Janeiro: Zahar, 2001, p. 11, diz: "Não devemos nos enganar: a mosca presa entre os dedos de uma pessoa luta tão convulsivamente quanto um ser humano entre as garras de um assassino, como se soubesse do perigo que corre".

6 Idem. Ibidem, p. 45. Ver também o pensamento de Ivan Ilitch, TOLSTÓI, Leon. Ibidem, p. 50 "Caio é de fato mortal e, portanto, é justo que morra, mas quanto a mim, o pequeno Vânia, Ivan Ilitch, com todos os meus sentimentos e minhas ideias, o caso é inteiramente outro. É impossível que eu tenha que morrer. Seria demasiado horrivel". É evidente que esse compartilhamento não é absoluto, havendo até mesmo animais que, em prol da preservação da sua comunidade, dão a própria vida em defesa do grupo. Assim ocorre com as abelhas que pagam com a própria morte o uso de seu ferrão. Desta maneira, mesmo a morte tem funções bem específicas dentro da ideia de seleção natural. Darwin diz que "desde que a ferroada tenha utilidade para toda a comunidade, isto por si só preenche os requisitos da seleção natural, ainda que acarrete a morte de alguns de seus membros". DARWIN, Charles. A origem das espécies. $4^{\mathrm{a}}$ ed. Belo Horizonte: Itatiaia, 2002, p. 181

$7 \quad$ ELIAS, Norbert. Ibidem, p. 8-9. 
O reconhecimento da morte como algo ínsito ao destino humano permite, em um primeiro momento, que qualquer pessoa coloque-se em pé de igualdade com o próximo ${ }^{8}$. A finitude aproxima já que, na morte, todos são iguais. A condição da morte como destino presente e inevitável de todo o ser humano seria uma das bases de todas as culturas humanas $^{9}$ que tentam, de uma forma ou de outra, permitir a vida tendo em conta a presença da morte ${ }^{10}$. Tanto é assim que uma das invenções culturais mais importantes da humanidade é a própria negação da morte, indicando que com a sua ocorrência passa-se a outro mundo ${ }^{11}$, tese encontrada em muitas das religiões ${ }^{12}$ e que se fundamenta no caráter transcendente da alma. Vira-se, assim, o sentido da morte, transformando "a queda mais repugnante na mais jubilosa ascensão" ${ }^{13}$. A obra continua permanecendo atual por tratar do difícil tema de como lidar com aqueles que estão prestes a morrer, demonstrando, já à época, um certo "constrangimento social"14 que ainda persiste até hoje.

É evidente que há uma ligação direta entre a obra e o Direito, pois Ivan Ilitch é um juiz e, em diversas passagens, o autor fala sobre seu trabalho na corte, sua relação com os advogados e as partes, etc. Porém, para além dessa evidente relação, o presente artigo

8 Mas também permite ver o outro como um diferente, principalmente, se doente ou vulnerável. MARQUES, Cláudia Lima; MIRAGEM, Bruno. O novo direito privado e a proteção dos vulneráveis. São Paulo: RT, 2012, p. 108-109: "Esta ideia do 'outro como espelho' nos é muito importante, pois marca até hoje a nossa visão da 'diferença': a imagem refletida é sempre uma 'verdade' invertida, igual, mas diferente! Em outras palavras, o 'outro', o 'diferente' seve para nos olharmos, dai que se valoriza ao extremo a diferença. Esta visão do outro como espelho destaca também a 'distância' entre um e outro estamento ou status, valorizando as diferenças e considerando que o tratamento deve ser 'protetivo' e evitar qualquer discriminação do mais fraco".

9 ELIAS, Norbert. Ibidem,p. 43-44. O autor afirma que "o encobrimento e o recalcamento da morte, isto é, da finitude irreparável de cada existência humana, na consciência humana, são muito antigos. Mas o modo do encobrimento mudou de maneira específica com o correr do tempo".

10 BAUMAN, Zygmunt. Ibidem, p. 46: "Todas as culturas humanas podem ser decodificadas como mecanismos engenhosos calculados para tornar suportável a vida com a consciência da morte".

11 Idem. Ibidem.

12 Diz Mario Vargas Llosa que: "Cultura e religião não são a mesma coisa, mas não são separáveis pois a cultura nasceu dentro da religião e, embora com a evolução histórica da humanidade tenha ido se afastando parcialmente dela, sempre estará unida à sua fonte nutridora por uma espécie de cordão umbilical”, p. 14. Ver também, p. 33-34 "A religião, enquanto dura, e em seu próprio campo, dá um sentido conveniente à vida, proporciona o arcabouço para a cultura e protege a massa da humanidade do tédio e do desespero". LLOSA, Mario Vargas. A civilização do espetáculo: Uma radiografia do nosso tempo e da nossa cultura. Rio de Janeiro: Objetiva, 2013.

13 BAUMAN, Zygmunt. Ibidem, p. 48. ELIAS, Norbert. Ibidem, p. 14, afirma também que as crenças na vida após a morte são mais intensas e apaixonadas "naquelas classes e grupos cujas vidas são mais incertas e menos controláveis".

$14 \quad$ ELIAS, Norbert. Ibidem, p. 77. 
busca tratar o personagem principal como um doente apontando a natural vulnerabilidade das pessoas em tais condições.

Em determinado momento da estória, Ivan Ilitch passa a notar que é na presença de seu criado Guerássim que se sente melhor. Essa constatação do personagem demonstra a importância do cuidado para o doente e evidencia a grande vulnerabilidade das pessoas em tais condições. Nota Ivan Ilitch, em seu sofrimento, que apenas seu criado, na realidade, o compreendia e se compadecia realmente de sua condição ${ }^{15}$. A relação entre Ivan Ilitch e Guerássim é, talvez, um dos pontos mais importantes do livro. Sua atenção ao doente faz até que se construa "uma intimidade inimaginável entre um senhor e um servo na Rússia czarista do século XIX"16. A dor do personagem principal é a dor da "ausência de compaixão" de todos que o rodeiam ${ }^{17}$, à exceção de Guerássim. É possível dizer que Tolstói prevê a invenção de um novo modo de cuidar humanizado ${ }^{18}$ com a relação entre os dois personagens. Não se nega a ideia de que o que pode ser feito, muitas vezes, em relação aos doentes terminais, é apenas a amizade e o cuidado dos que estão perto e a transmissão do sentimento de que eles não "não causam embaraço aos vivos"19.

Percebe-se que Ivan Ilitch não encontrava o mesmo conforto com sua família. A filha do personagem é retratada como "forte, sadia, visivelmente apaixonada, e irritada com a doença, os padecimentos e a perspectiva da morte, porque perturbavam a sua felicidade ${ }^{20}$, o que certamente era notado. Tolstoi indica, no início da obra, a preocupação da mulher de Ivan Ilitch quanto aos assuntos relativos à pensão, manifestados logo quando do velório do marido. É curioso o retrato dessa indiferença pois se sabe que uma das experiências mais próximas da morte que um ser humano pode experimentar é a morte de um companheiro, que representa quase uma "morte de segundo grau" ${ }^{21}$.

15 TOLSTÓI, Leon. Ibidem, p. 56. Era com Guerássim que Ivan Ilitch encontrava até mesmo alívio da própria dor, pois este o ajudava a ficar em uma posição que a diminuía.

16 CECILIO. Luis Carlos de Oliveira. A morte de Ivan Ilitch, de Leon Tolstói: elementos para se pensar as múltiplas dimensões da gestão do cuidado. Interface - Comunicação, Saúde, Educação. V. 13, supl. I, p. 545-555, 2009, p. 547. Tanto que o criado passa a tratar Ivan Ilitch por "tu".

17 FAUSTINO, Jean Carlo. A morte de Ivan Ilich: onde Tolstói, Dostoiéviski e Norbert Elias se encontram. Fragmentos, n. 38, p. 121-135, jan.-jun./2010, p. 133.

18 CECILIO. Luis Carlos de Oliveira. Ibidem, p. 548. Este autor diz que se trata de "uma 'tecnologia de cuidado' que nasce do gesto, da proximidade fisica, da escuta e da generosidade do 'cuidador".

19 ELIAS, Norberto. Ibidem, p. 77.

20 Idem. Ibidem, p. 63.

21 BAUMAN, Zygmunt. Ibidem, p. 62. Já Heiddeger diz que "a morte dos outros, porém, se torna tanto mais penetrante pois o findar da pre-sença é objetivamente acessivel" HEIDEGGER, Martin. Ser e Tempo: Parte II. 13 a ed.. Petrópolis: Vozes, 2005, p. 17. 
Se os episódios passados de sua vida pareciam agradáveis e importantes, agora, quando analisados em sua nova condição de doente terminal, parecem perder o sentido. Ao reavaliar sua vida Ivan Ilitch percebe que os momentos que antes eram agradáveis e importantes, agora, não pareciam mais assim ${ }^{22}$; chega a pensar ele que talvez não tenha vivido como deveria ${ }^{23}$. Talvez tenha conseguido notar que foi um egoísta por toda a vida, o que o assombra ${ }^{24}$. Mesmo para um juiz, que se gabava de cumprir estritamente a lei, foi possível chegar a esta conclusão e isso o atordoava: "quando lhe vinha a ideia de que não vivera como deveria, o que amiudadamente acontecia, lembrava-se logo da correção da sua vida e repelia o insólito pensamento" ${ }^{25}$. No entanto, de que se trata essa correção? Ivan Ilitch estaria se referindo à correção "jurídica" de sua vida? Neste sentido, é possível recorrer à André Comte-Sponville. Este autor indica que nenhuma lei veda o egoísmo, o desprezo, o ódio e a maldade. Assim, mesmo um cumpridor das leis pode ser o que ele chama de "canalha legalista"26.

É claro que o aspecto "jurídico" da vida, envolvendo a análise da "licitude" das próprias ações ações, não foi suficiente para a avaliação feita por Ivan Ilitch. Na verdade, o aspecto jurídico é apenas um dos aspectos da vida humana. Silvio Romero indica que existiriam sete "classes" ou "fenômenos culturais" que compõem a civilização humana e o Direito seria apenas um destes fenômenos. ${ }^{27}$

O avaliação feita por Ivan Ilitch de toda a sua vida, quando no leito de morte, retrata a eterna tensão que envolve as avaliações sobre os próprios atos. Pode-se chamar isso de "sorte moral" que envolve "o reconhecimento da tensão que sempre perdura na nossa condição humana, a tensão entre a nossa vontade de comandarmos $e$

22 TOLSTÓI, Leon. Ibidem, p. 66.

23 Idem. Ibidem, p. 67.

24 ELIAS, Norbert. Ibidem, p. 72: "O modo como uma pessoa morre depende em boa medida de quela tenha sido capaz de formular objetivos e alcançá-los, de imaginar tarefas e realizá-las [...] podemos talvez supor que morrer é mais fácil para aqueles que acreditam terem feito a sua parte....

25 Idem. Ibidem.

26 COMTE-SPONVILLE, André. O capitalismo é moral? São Paulo: Martins Fontes, 2011, p. 54-55. O "canalha legalista" pode ser definido como aquele que dedica "respeito completo, escrupuloso, intransigente de toda a legalidade. E nada tampouco para escapar desse espectro na primeira ordem: um canalha legalista pode ser cientificamente competente, tecnicamente eficiente; com o que será com certeza mais eficaz, talvez mais perigoso, mas nem por isso deixará de ser um canalha". Na visão do autor é justamente o espectro do canalha legalista que move o ser humano às ordens éticas e morais, sem as quais, a vida seria impossível.

27 ROMERO, Sílvio. Ensaios de filosofia de direito. São Paulo: Landy, 2001, p. 101. Os sete fenômenos são: ciência, religião, arte, política, moral, direito e indústria.. 
transformarmos o mundo e a resistência que o mundo oferece, vulnerabilizando-nos" ${ }^{28}$. O vocábulo "sorte", aqui, deve ser interpretado levando-se em conta o fato de que às vezes, aos atos escapam as consequências em função da falta de intenção e previsão. Também, a "sorte" leva em conta aspectos como "a nossa própria biografia propiciou a sedimentação do nosso carácter moral" ${ }^{29}$. Assim, é possível questionar até que ponto Ivan Ilitch poderia ter agido diferente em função de suas influências de vida. Quanto à sua biografia, a obra não dá muitos detalhes de sua vida na infância, embora destaque que ele, desde então, sentia-se "naturalmente atraído pelas pessoas que ocupavam posição elevada na sociedade, tal como as mariposas pela luz, e assimilava-lhes as maneiras e as opiniões..."30. Também, mesmo que o autor não se manifeste diretamente sobre a relação do personagem com seu pai, pode-se percebê-la como distante. O pai de Ivan Ilitch, registre-se, era um "funcionário inútil de várias repartições supérfluas"11 o que, sem dúvida, influenciou na formação da personalidade de seu filho.

O sentimento de que sua vida não foi importante retrata a importância da consideração da morte para a vida humana. Tanto é assim que foi somente quando confrontado com a morte iminente que Ivan Ilitch chega a tal conclusão. Por isso que a consideração da morte é vista como uma das formas de dar propósito à vida, tornando preciosos os momentos vividos ${ }^{32}$.

É possível notar, logo no início da obra, referências ao fato de Ivan Ilitch ter se entregue à vaidade e que sua vida fora "das mais simples, das mais vulgares e, contudo, das mais terríveis" ${ }^{33}$. Se sua alegria maior, que encontrava no trabalho "era a alegria da ambição", já na vida social sustentava a alegria da vaidade ${ }^{34}$. Foram feitas interpretações desta obra no sentido de apontar que a solidão do personagem ter-se-ia dado em função da "sina de alguém egoísta que acabou recebendo uma espécie de punição existencial por ter,

28 ARAÚJO, Fernando. Sorte Moral, Carácter e Tragédia Pessoa. Revista do Instituto de Direito Brasileiro. Ano 2, n. 1, p. 1-71, 2013, p. 4.

29 ARAÚJO, Fernando. Ibidem, p. 4.

30 TOLSTÓI, Leon. Ibidem, p. 21.

31 Idem. Ibidem.

32 BAUMAN, Zygmunt. Ibidem, p. 47.

33 TOLSTÓI, Leon. Ibidem, p. 20.

34 Idem. Ibidem, p. 36. Sobre sua vaidade, ver a seguinte passagem: "A consciência da sua força, que permitia aniquilar quem ele quisesse, a imponência da sua entrada no tribunal, a deferência que lhe tributavam os subalternos, seus exitos com superiores e subordinados e, sobretudo, a maestria com que conduzia os processos criminais e da qual se orgulhava - tudo isto lhe dava prazer...", p. 29. Tanto que seu próprio casamento se dera muito mais por fins sociais do que pelo amor que sentia por sua nova esposa (p. 26), o que talvez possa ter sido um dos motivos de seus constantes conflitos. 
durante toda a vida, procurado somente seus interesses" ${ }^{35}$. É interessante notar que a mesma indiferença e distanciamento burocrático que Ivan Ilitch mantém em seu ofício de juiz pode ser observado também nos médicos que o atendem.

É presente também sua fixação pelo seu cargo público talvez, muito mais, pelo símbolo de status do que pela honradez da profissão. Após situações envolvendo questões de sua não promoção, Ivan Ilitch considera uma viagem "a fim de manobrar para que fossem castigados aqueles que não haviam reconhecido os seus méritos" ${ }^{36}$. Da mesma forma, vê-se seu contentamento quando, após sua promoção, ele conversa com a família contando "como fora obsequiado em Petersburgo, como humilhara os seus antigos inimigos, que agora o adulavam e o invejavam, e como toda gente gostava dele na capital" $^{\prime 37}$. Todo o comportamento egoísta de Ivan Ilitch também manifesta-se em seus colegas que, em seu velório, estão mais preocupados nas oportunidades de promoção abertas pela morte daquele. ${ }^{38}$

Se o sentimento de inveja e da vaidade são da própria natureza humana a luta contra tais sentimentos também são reconhecidos, o que é evidenciado pelo dilema existencial do personagem. Por outro lado, o medo da morte também é presente e, talvez, nunca foi tão presente como na sociedade moderna. A ampliação da expectativa de vida, o culto ao corpo, a "proibição da tristeza" e a diversão a qualquer custo ${ }^{39}$, o consumismo exacerbado, as pessoas vistas como mercadoria ${ }^{40}$, a resistência e incapacidade dos pais tratarem do assunto "morte" com os filhos ${ }^{41}$, a diminuição progressiva da violência ${ }^{42}$, tudo isso e muito mais eleva as pessoas quase a figura de deuses que não admitem sua morte ${ }^{43}$.

35 FAUSTINO, Jean Carlos. Ibidem, p. 121.

36 Idem. Ibidem, p. 30.

37 Idem. Ibidem, p. 31.

38 Segundo FAUSTINO, Jean Carlos. Ibidem, p. 123, a obra retrata a forma que um grupo social encara a morte.

39 LLOSA, Mario Vargas. Ibidem, p. 123: "A raiz do fenômeno está na cultura. Ou melhor, na banalização lúdica da cultura imperante, em que o valor supremo é agora divertir-se, acima de qualquer outra forma de conhecimento ou ideal."

40 Zygmunt Bauman aponta que as pessoas devem se tornar" uma mercadoria atraente e desejável" no intuito de se promoverem e se venderem em uma sociedade altamente consumista. BAUMAN, Zygmunt. Vida para o consumo: a transformação das pessoas em mercadoria. Rio de Janeiro: Zahar, 2008, p. 13

41 ELIAS, Norbert. Ibidem, p. 26: “Antigamente as crianças também estavam presentes quando as pessoas morriam".

$42 \quad$ Idem. Ibidem, p. 57.

43 Embora seja característica do ser humano o "sonho da imortalidade". As razões psicanalíticas seriam "fortes sentimentos de culpa recalcados, talvez ligados a desejos de morte em relação ao pai, à mãe e aos irmãos, com o temor de desejos análogos da parte deles", cf. ELIAS, Norbert. Ibidem, p. 17. 
Ainda assim, a morte é inafastável até para toda essa nova horda de semideuses - que tanto já incomodavam Fernando Pessoa ${ }^{44}$.

Há, é verdade, novos estratagemas para que as pessoas lidem com a medo da morte. Atualmente, pode-se notar a "marginalização das preocupações com o fim", tudo com o intuito de afastar a preocupação com a eternidade ${ }^{45}$. Busca-se afastar, reduzir e degradar o "valor da duração" fazendo com que apenas o "agora" seja importante e não mais o "depois"46. Faz-se isso tanto pela desconstrução da morte quanto pela sua banalização 47 .

Zygmunt Bauman diz, também, que "a morte é aterradora por essa qualidade específica - a de tornar todas as outras qualidades não mais negociáveis" ${ }^{48}$. Tudo o que existe para os vivos e todas as condições que o mundo físico permite apreciar cessam com a morte $^{49}$. A morte é, assim, o maior exemplo do desconhecido ${ }^{50}$.

A consideração da morte, levando em conta seus efeitos jurídicos, é encontrada em todas as áreas do direito, do direito civil até o direito penal. A existência da pessoa natural termina com a morte, de acordo com o art. $6^{\circ}$ do $\mathrm{CC}$ permitindo-se, em alguns casos, a declaração da morte presumida, conforme o art. $7^{\circ}$ do mesmo diploma.

A vida - o oposto da morte - é o bem jurídico mais importante, talvez da maior parte dos ordenamentos jurídicos de países democráticos ${ }^{51}$. No caso brasileiro, a Constituição $^{52}$ prevê a impossibilidade da aplicação da pena de morte, exceto, em casos de guerra. Protege-se não apenas a vida humana mas também à vida dos animais - que também compartilham com os homens, via instinto de preservação, a aversão à morte. Se é

44 Segundo a célebre passagem do "Poema em Linha Reta" do autor: "Arre, estou farto de semideuses! Onde há gente no mundo?".

45 BAUMAN, Zygmunt. Medo.., p. 56.

46 Idem. Ibidem, p. 56-57.

47 Embora ELIAS, Norbert. Ibidem, p. 21, afirme que a morte era tema mais aberto e frequente na Idade Média do que hoje.

$48 \quad$ Idem. Ibidem, p. 44.

49 Na verdade, é o que observa a ciência até o momento. Várias religiões e crenças, como se disse, trabalham justamente na compreensão do caráter transcendente do ser. A afirmação de que tudo acaba com a morte é feita dentro de um contexto sociológico e jurídico sem observar as questões transcendentais e as crenças pessoais deste autor (que não teriam espaço e nem importância no âmbito deste estudo).

$50 \quad$ Idem. Ibidem, p. 44-45. "quando se trata de traçar um limite verdadeiramente intransponível à imaginação humana, a morte não tem concorrentes...".

51 É claro que tal afirmação é formal pois, nem sempre, se procede à proteção efetiva da vida, principalmente, quando há custos econômicos para tal. Essa questão já foi notada pelos teóricos da Análise Econômica do Direito que chegam a afirmar que "nossa sociedade não está comprometida a preservar a vida a qualquer custo", cf. CALABRESI, Guido. The Costs os Accidents: A Legal and Economic Analysis. New Haven: Yale University Press, 1970, p. 17.

52 Art. $5^{\circ}$, inc. XLVII, a. 
verdade que o homem mata animais, de forma deliberada e pelos mais variados propósitos, nota-se, por outro lado, uma crescente preocupação do Direito com a vida animal. A França, em um incrível ato que representa talvez uma das maiores modificações em todo o Direito Civil, passou a reconhecer - via alteração a ser ainda realizada em seu Code Civil que os animais são não apenas coisas ou bens móveis mas "seres vivos dotados de sensibilidade", o que importa em uma modificação relevante na divisão clássica entre pessoas e coisas. $^{53}$

Ainda que Ivan Ilitch não quisesse sua morte, há casos de pacientes terminais que querem sim dar cabo da própria vida. Assim, emerge a polêmica prática do chamado "suicídio assistido" para pacientes terminais que sofrem com suas moléstias. Sabe-se que países como Bélgica, Colômbia, Holanda, Luxemburgo, Suíça e alguns estados dos EUA permitem o suicídios assistido ${ }^{54}$. No Oregon existe a Lei da Morte com Dignidade que permite o suicídio assistido caso um diagnóstico aponte que a morte ocorrerá dentro de seis meses. Já na Holanda o critério é um "sofrimento insuportável sem expectativa de melhora" ${ }^{\text {"55 }}$. Embora o direito ao suicídio assistido viole, em um primeiro momento, o próprio direito à vida, está de acordo, segundo Luis Roberto Barroso, com o direito à integridade física e mental e também o direito à autonomia. Existe assim, com base nisto, um direito a morrer com dignidade sem ser obrigado a sofrer caso não queira ${ }^{56}$.

Feitas essas breves considerações sobre vida e morte e a jornada existencial do personagem, passa-se a análise da vulnerabilidade do doente.

\section{O doente visto como um (hiper)vulnerável}

53 LE MONDE. Les animaux sont désormais officiellment "dués de sensibilité". 28.01.2015. Disponível em: $\quad<$ http://www.lemonde.fr/planete/article/2015/01/28/les-animaux-sont-desormaisofficiellement-doues-de-sensibilite_4565410_3244.html>

54 BARROSO, Luis Roberto. "Aqui, lá e em todo lugar": a dignidade humana no direito contemporâneo e no discrusos transnacional. In: BOGDANDY, Armin von; et all. Estudos avançados de Direitos Humanos: Democracia e Integração Jurídica: Emergência de um novo Direito Público. São Paulo: Elsevier, 2013, p. 460.

55 Idem. Ibidem.

56 Idem. Ibidem, p. 461. 
Revista Diálogos do Direito

http://ojs.cesuca.edu.br/index.php/dialogosdodireito/index

\section{Cesuca}

ISSN 2316-2112

Na Modernidade (séculos XV a XIX) a medicina ficou marcada pela característica de ser desumanizada sendo que, frequentemente, o doente era visto como um degradado ${ }^{57}$. $\mathrm{O}$ século XX amplia essa condição por meio de práticas tecnológicas "altamente especializadas e racionalistas", o que Fernanda Schaefer chama de Medicina Tecnocêntrica. Seria, segundo a autora, apenas no século XXI que passa a se repensar a medicina com uma preocupação na humanização e democratização do indivíduo ${ }^{58}$. Embora as datas apontadas por Schaefer pareçam exageradas e, em uma perspectiva do senso comum, parece difícil aceitar que um cuidado humanizado nasce apenas no século XXI, infelizmente a realidade parece ser esta. É comum ver, ainda hoje, notícias de idosos sendo "depositados" em instituições de cuidado que não teriam condições de abrigar nem mesmo animais ${ }^{59}$, o que representa um grande paradoxo entre o discurso e a realidade.

Nas sociedades pré-modernas, o convívio com a morte e com a doença eram mais naturais do que na atualidade ${ }^{60}$. Se havia essa desumanização da medicina, havia, por outro lado, uma proximidade maior entre os doentes e seus familiares ${ }^{61}$. A obra de Tolstói permite enxergar a tensão de uma sociedade que não consegue mais lidar adequadamente com o doente sendo tratado na própria casa. Todo o desconforto da família com Ivan Ilitch podem ser um indicativo dessa questão. A tensão retrata também a passagem entre momentos históricos diferentes no tratamento da morte ${ }^{62}$. Mesmo assim, ainda hoje, dar aos moribundos ajuda e afeição continua sendo um grande problema para a sociedade atual $^{63}$.

57 SCHAEFER, Fernanda. A nova concepção do consentimento esclarecido. Revista do Instituto de Direito Brasileiro. Ano 1, n. $1 O$ que às vezes reconfortava os moribundos no passado era a presença de outras pessoas 0 , p. 6317-6354, 2012, p. 6319.

58 SCHAEFER, Fernanda. Ibidem, p. 6320. Mesmo assim, os hospitais, ainda hoje, são um espaço de segregação da morte e da doença conforme GIDDENS, Anthony. Modernidade e identidade. Rio de Janeiro: Jorge Zahar, 2002, p. 150.

59 Talvez um grande paradoxo dos tempos atuais é que, às vezes, as famílias cuidam melhor dos seus animais domésticos do que de seus idosos.

60 Idem. Ibidem, p. 150

61 ELIAS, Norbert. Ibidem, p. 22-23: “O que às vezes reconfortava os moribundos no passado era a presença de outras pessoas". Embora as pessoas sofressem mais na idade média e a vida fosse muito mais difícil do que na atualidade, a "participação dos outros na morte de um indivíduo era muito mais comum".

62 FAUSTINO, Jean Carlo. Ibidem. p. 132?: "Tolstói parece estar querendo dizer, dentre outras coisas, que a despeito de qualquer progresso ou promessa de desenvolvimento propiciado pelas tendências modernizantes de seu país, a maneira de experimentar a morte, nesta nova ordem social, era não somente insuficiente como cruel para quem está se despedindo da vida..."

63 ELIAS, Norbert. Ibidem, p. 16-17. Diz o autor que isto ocorre, principalmente, pois a morte do outro lembra a própria morte daquele que observa: "A visão de uma pessoa moribundo abala as fantasias defensivas que as pessoas constroem como uma muralha contra a ideia de sua própria morte". 
É neste sentido, e com este pano de fundo, que é possível tratar a questão da vulnerabilidade do doente. De maneira geral, a consideração do princípio da vulnerabilidade previsto no CDC, em seu art. $4^{\circ}$, inc. I, é uma presunção legal absoluta ${ }^{64}$. Todo o consumidor, em uma relação de consumo, está em uma posição de vulnerabilidade $^{65}$ em relação ao fornecedor. A vulnerabilidade do consumidor é um "superprincípio" e também um "pressuposto fático necessário à justa equação das relações de consumo" "66. Há mais de um tipo de vulnerabilidade, sendo que a doutrina considera a técnica, a jurídica e a fática (esta última quando o consumidor possui alguma característica concreta que evidencie um estado de debilidade como a criança, o idoso, o analfabeto, doente, etc ${ }^{67}$. O vulnerável, na relação de consumo, é a parte mais fraca, debilitada em função de "condições ou qualidades que lhe são inerentes..."68. Ela pode ser vista também como um "estado inerente de risco" e "uma situação permanente ou provisória, individual ou coletiva, que fragiliza, enfraquece o sujeito de direitos, desequilibrando a relação" 69 .

Já a vulnerabilidade do doente é uma vulnerabilidade fática especial "em vista de sua situação de debilidade física"70 e, também mental. Porém, o doente não é apenas vulnerável mas sim um hipervulnerável ${ }^{71}$. Não há uma definição específica sobre quem

64 MARQUES, Cláudia Lima. Contratos no Código de Defesa do Consumidor: O novo regime das relações contratuais. $7^{\mathrm{a}}$ ed. Rev. Atual. e amp. São Paulo: RT, 2014, p. 358. No mesmo sentido, MIRAGEM, Bruno. Curso de Direito do Consumidor. 3a ed. São Paulo: RT, 2012, p. 99

65 Ver FAVIER, Yann. Trad. AQUINI, Vinícius; BERTONCELLO, Káren Rick Danilevicz. A inalcançável definição de vulnerabilidade aplicada ao direito: abordagem francesa. Revista de Direito do Consumidor, n. 70, p. 15-24, jan.-fev./2013, p. 21, quando fala sobre a "crescente utilização do termo vulnerabilidade no discurso jurídico". Diz o autor que "Mais que técnica, a utilização do termo vulnerabilidade parece destacar uma política. Como existe uma política familiar que se apoia especialmente em instrumentos jurídicos (o direito das prestações familiares, a ajuda e a ação social familiares, etc), a política em favor das pessoas vulneráveis, principalmente em razão da idade ou da deficiência, a exemplo da proteção dos consumidores, utiliza dispositivos jurídicos variados que não formam verdadeiramente uma unidade conceitual".

66 AMARAL, Luiz Otávio de Oliveira. Teoria Geral do Direito do Consumidor. São Paulo: RT, 2010, p. 65 .

67 MIRAGEM, Bruno. Ibidem, p. 100-102.

68 Idem. Ibidem, p. 100.

69 MARQUES, Cláudia Lima; MIRAGEM, Bruno. Ibidem, p. 117.

70 Idem. Ibidem, p. 102.

71 MARQUES, Cláudia Lima. Ibidem, p. 362: "Parece-me, porém, que a vulnerabilidade agravada é, assim como a vulnerabilidade, um estado subjetivo multiforme e pluridimensional, e que, com base no principio da igualdade (aequitas) e da equidade, podem ser incluidos outros "fracos", como as minorias mais frágeis e os doentes, por exemplo". Também o próprio art. 39, IV do CDC estabelece, como prática 
seriam os hipervulneráveis, sendo ainda cedo para afirmar se são apenas aqueles presentes na Constituição (crianças, adolescentes, idosos e portadores de deficiência) ou se o rol pode ser ampliado: tudo dependerá do caso concreto, segundo Cláudia Lima Marques ${ }^{72}$. Mesmo assim, defende-se que o rol pode sim ser ampliado de forma a abarcar novas formas de vulnerabilidade. Assim, diante de cada caso é possível, em uma verificação fática, identificar tipos de consumidores que possuem uma vulnerabilidade agravada.

O conceito de hipervulnerabilidade, segundo Cláudia Lima Marques, seria:

"a situação social, fática e objetiva de agravamento da vulnerabilidade da pessoa física consumidor, por circunstâncias pessoais, aparentes ou conhecidas do fornecedor, como sua idade reduzida [...] ou sua idade alentada [...] ou sua situação de doente (assim o caso do glúten ${ }^{73}$ e as informações na bula de remédios"74.

Sabe-se que os hipervulneráveis são justamente aquelas figuras discriminadas e ignoradas, também, os que "mais sofrem com a massificação do consumidor e a 'pasteurização' das diferenças que caracterizam e enriquecem a sociedade moderna."75. Se a vulnerabilidade normal é um estado inerente de todos os consumidores, a hipervulnerabilidade acompanharia a situação especial do consumidor, quer seja a situação permanente ou temporária ${ }^{76}$ (incluindo-se, nos dois casos, a doença). É claro que, no conceito de vulnerabilidade, percebe-se uma certa heterogeneidade das situações tratadas o que pode trazer uma certa incerteza sobre seu real conteúdo ${ }^{77}$. Tal consideração poderia levar ao perigo de se conceber como vulnerável todo aquele exposto a um risco social ou

abusiva, "prevalecer-se da fraqueza ou ignorância do consumidor, tendo em vista sua idade, saúde, conhecimento ou condição social, para impingir-lhe seus produtos ou serviços;"

72 Cf. MARQUES, Cláudia Lima. O "diálogo das fontes" como método da nova teoria geral do direito: um tributo à Erik Jayme. In: Idem (coord). Diálogo das fontes: do conflito à coordenação de normas no direito brasileiro. São Paulo: RT, 2012, p. 42 e 48. A autora afirma que enquanto os hipervulneráveis estipulados na CF beneficiam-se do mandamento de proteção constitucional, "os doentes e analfabetos são hipervulneráveis cuja proteção especial dependerá da atuação ativa do Judiciário e das especificidades do caso concreto (por exemplo, conhecimento pelo parceiro contratual de sua condição agravada de vulnerabilidade, tipo de contrato, onerosidade ou gratuidade deste, etc)."

73 O caso do glúten, citado pela autora, refere-se a: SUPERIOR TRIBUNAL DE JUSTIÇA. $2^{\mathrm{a}}$ Turma. REsp. 586.316/MG. Rel. Herman Benjamin. J. em 17.04.2007.

74 MARQUES, Cláudia Lima. Contratos..., p. 359-360.

75 De acordo com o REsp. 586.316/MG.

76 MARQUES, Cláudia Lima. Contratos..., p. 362.

77 Cf. FAVIER, Yann. Ibidem, p. 23. 
individual $^{78}$, o que não se defende aqui. Se todos forem considerados hipervulneráveis, na realidade, ninguém o será.

A fragilidade do hipervulnerável pode ser amplamente notada na obra de Tolstói, principalmente, nas situações em que Ivan Ilitch sequer consegue cuidar propriamente de suas necessidades mais básicas. No caso concreto, a hipervulnerabilidade é maior ainda quando se trata de pessoa idosa ${ }^{79}$ e doente, pois reúne, assim, dois atributos que levam à hipervulnerabilidade. Nada impede que, na mesma pessoa, existam vários atributos ou situações fáticas que levem à hipervulnerabilidade. Assim, um idoso, doente e analfabeto encontra-se, talvez, no mais alto grau de vulnerabilidade possível.

A vulnerabilidade do doente amplia-se também nos casos de doentes mentais ${ }^{80}$. Até antes da ampliação da psiquiatria como ciência ${ }^{81}$ a loucura era vista como um "desregramento moral" ${ }^{82}$. Não raro, tal condição mental era equiparada ao crime ${ }^{83}$. Não se deve esquecer que, na Alemanha nazista, Hitler criou um programa de eutanásia que foi inicialmente aplicado aos doentes mentais. Sabe-se que entre 1939 e 1941 "cerca de 50 mil alemães foram mortos com monóxido de carbono" ${ }^{14}$.

As pessoas com transtornos mentais, não raras vezes, são abandonados pelas famílias passando ou a viver na rua ou em instituições específicas de cuidado. Em muitas situações tais instituições são fechadas e representam uma barreira da pessoa lá internada com o mundo externo ${ }^{85}$, perdendo, o doente, seu direito a se socializar. Assim, o fato natural das pessoas viverem, trabalharem, estudarem e se divertirem em locais distintos

78 Idem. Ibidem.

79 Sobre o tema ver SCHMITT, Cristiano Heineck. A "hipervulnerabilidade" do consumidor idoso. Revista de Direito do Consumidor. v. 70, p. 139-171, abr.-jun./2009, versão online.

80 Cf. reconhece o SUPERIOR TRIBUNAL DE JUSTIÇA. 2 ${ }^{\mathrm{a}}$ Turma. REsp. 931513-RS. Rel. Min. Carlos Fernando Mathias (Juiz Federal Convocado do TRF $1^{\text {a }}$ Região). J. em 25.11.2009: “A categoria éticopolítica, e também jurídica, dos sujeitos vulneráveis inclui um subgrupo de sujeitos hipervulneráveis, entre os quais se destacam, por razões óbvias, as pessoas com deficiência física, sensorial ou mental'.

81 Sobre o assunto ver MACHADO, Roberto et al. Danação da norma: medicina social e constituição da psiquiatria no Brasil. Rio de Janeiro: Graal, 1978.

82 MUSSE, Luciana Barbosa. Novos sujeitos de direito: as pessoas com transtorno mental na visão da bioética e do biodireito. São Paulo: Elsevier/Campus Jurídico, 2008, p. 36.

83 Idem. Ibidem.

84 HARENDT, Hannah. Eichmann em Jerusalém: Um relato sobre a banalidade do mal. São Paulo: Companhia das Letras, 1999, p. 122 e 124. Hannah Harendt registra que embora muitos se revoltaram contra o asfixiamento de doentes mentais - inclusive algumas Igrejas o fizeram - o mesmo não ocorreu com tanta ênfase quando da morte dos judeus, p. 126.

85 GOFFMAN, Erving. Manicômios, prisões e conventos. São Paulo: Perspectiva, 1974, p. 16. 
não ocorre em tais instituições ${ }^{86}$. Em muitas situações, o tratamento é completamente desumano, inclusive, com o absoluto distanciamento social entre funcionários e doentes ${ }^{87}$.

Mesmo diante da circunstância de alguém estar ou ser um doente mental, isto não retira da pessoa o fato de ela ser um sujeito de direitos. As características apontadas por Goffman sobre as instituições de cuidado, atualmente, não encontram respaldo na lei ${ }^{88}$. A despeito das muitas legislações passadas que lidavam com o tema da doença mental ${ }^{89}$ vige atualmente, no Brasil, a lei 10.216/2001, que "Dispõe sobre a proteção e os direitos das pessoas portadoras de transtornos mentais e redireciona o modelo assistencial em saúde mental" ${ }^{\prime 0}$. $\mathrm{O}$ art. $2^{\circ}$ desta lei, trata alguns dos direitos dos pessoas portadoras de doenças mentais, entre eles, o inc. II (ser tratada com humanidade e respeito e no interesse exclusivo de beneficiar sua saúde, visando alcançar sua recuperação pela inserção na família, no trabalho e na comunidade), VI (ter livre acesso aos meios de comunicação disponíveis), VII (receber o maior número de informações a respeito de sua doença e de seu tratamento) e IX ( ser tratada, preferencialmente, em serviços comunitários de saúde mental $)^{91}$.

Outra características das instituições de cuidado para pessoas com distúrbios mentais é o controle das comunicações e o não conhecimento sobre as decisões que afetam seus destinos ${ }^{92}$. Eventuais práticas de tal natureza também não encontram respaldo na lei que prevê, como se viu, o direito de receber o máximo de informações sobre sua doença e tratamento.

De forma geral, tem a pessoa o direito a saúde como direito social fundamental, de acordo com o art. $6^{\circ}$ da CF. Tal consideração faz nascer, no Brasil, o Sistema Único de

$86 \quad$ Idem. Ibidem, p. 17.

87 Idem. Ibidem, p. 18.

88 Anthony Giddens afirma que "o que hoje chamamos hospital só gradativamente se diferenciou das organizações mais antigas que tentavam lidar com o impacto da pobreza. [...] O surgimento de uma espera separada de tratamento médico, focado em pessoas com 'problemas físicos' distintos, é parte dos mesmissmos processos que criaram outras organizações carcerárias". GIDDENS, Anthony. Modernidade e identidade. Rio de Janeiro: Jorge Zahar, 2002, p. 150.

89 Para um panorama histórico da legislação brasileira sobre o tema ver MUSSE, Luciana. Ibidem, $\mathrm{p}$. $34-41$.

90 Merece menção também, cf. MARQUES, Cláudia Lima; MIRAGEM, Bruno, p. 165, o Dec. 6949/2009 que promulgou a "Convenção Internacional sobre os direitos das pessoas com deficiência".

91 Segundo Luciana Barbosa Musse há também, os "Princípios para a proteção de pessoas acometidas de transtorno mental e para a melhoria da assistência a saúde mental", documento da ONU datado de 1999, p. 63-64.

92 GOFFMAN, Erving. Ibidem, p. 20. 
Saúde, conquista assegurada na CF no art. 198. Este direito passa também pela manutenção de uma série de políticas públicas aptas a cumprirem com a realização do direito à saúde ${ }^{93}$. Assim, a saúde vista como direito fundamental tem aplicabilidade imediata "e eficácia plena tanto em sua dimensão positiva quanto negativa" ", tratando-se de um direito social à prestação ${ }^{95}$.

Trata-se de cuidar não apenas dos aspectos físicos de um doente mas também de seus aspectos mentais, em consideração à própria dignidade da pessoa humana. É o chamado "respeito à integridade psíquica" do ser humano. Desta forma "se o espírito pertence à estrutura da pessoa e constitui parte integrante da sua personalidade, o tratamento psicoterapêutico encontra o seu limite natural no respeito da pessoa e das suas manifestações" ${ }^{196}$. É de se notar, neste âmbito, que o personagem Ivan Ilitch, a despeito de todos os seus medos e terrores, sofre sem um acompanhamento psicológico - certamente incomum à época em que a obra foi escrita mas que seria primordial em sua condição. Ele não é vulnerável apenas por estar com uma doença terminal mas também por um evidente quadro de depressão em função de sua condição. Há assim que considerar não apenas o aspecto físico da doença mas também seus reflexos mentais.

A relação médico paciente é bastante diferente de outras relações contratuais da vida cotidiana. A obra de Tolstói permite revelar todo o sofrimento psicológico pelo qual Ivan Ilitch passa, muitas vezes, sem acreditar no papel dos médicos que o atendem. Por isso, em tais relações, aparece um dever de informar especializado, ou seja, o dever de aconselhamento $^{97}$. Tal aconselhamento vai envolver a prestação de informações, pelo médico, relativas a quais remédios tomar, qual cirurgia fazer, qual tratamento se submeter

93 MUSSE, Luciana Barbosa. Ibidem, p. 68.

94 MATEUS, Cibele Gralha. Direitos fundamentais sociais e relações privadas: o caso do direito à saúde na Constituição brasileira de 1988. Porto Alegre: Livraria do Advogado, 2008, p. 138. Ingo Sarlet aponta, por outro lado, que há quem defenda que o direito à saúde dependeria de uma necessária “intermediação legislativa”, SARLET, Ingo Wolfgang. A eficácia dos direitos fundamentais: uma teoria geral dos direitos fundamentais na perspectiva constitucional. $10^{\mathrm{a}}$ ed. Porto Alegre: Livraria do Advogado, 2009, p. 324.

95 Segundo SARLET, Ingo Wolfgang. Ibidem, p. 200.

96 CHAVES, Antônio. Os direitos fundamentais da personalidade moral (à integridade psíquica, à segurança, à honra, ao nome, à imagem, à intimidade). Revista de Informação Legislativa. Ano 15, n. 58, p. 157-180, abr.-jun./1978. 162.

97 Há um dever de informar e de "tornar acessíveis e compreensíveis ao leigo (no caso, hipervulnerável, por se tratar de consumidor-doente) as informações técnicas sobre o produto, a fim de que

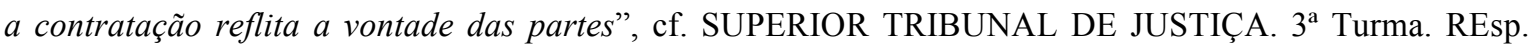
1.499.111-RS . Rel. Min. Moura Ribeiro. J. em 28.11.2014. 
contemplando as diversas variáveis - inclusive os riscos - de tal atividade ${ }^{98}$, tudo visando o construir um "consentimento informado" para as decisões tomadas pelo doente ${ }^{99}$. Ivan Ilitch sente-se incompreendido. As pessoas a sua volta - incluindo os médicos - não o entendem adequadamente. Daí a importância da obra para a compreensão de como é fundamental um dever de informar adequado para o doente.

Se há um dever de informação qualificado nas relações médicas, ao se considerar a boa-fé objetiva, verifica-se também um dever ampliado de cuidado. $\mathrm{Na}$ verdade, nas relações médicas, o dever de cuidado é muitas vezes a obrigação principal ${ }^{100}$ e não um dever anexo ${ }^{101}$. Este dever de cuidado impede, entre outras coisas, que os planos de saúde exijam o pagamento prévio de eventuais de dívidas como condição para a prestação de serviços envolvendo a manutenção da vida e da saúde ${ }^{102}$. É preocupante, como nota a doutrina, em relação às pessoas idosas, - que passam, sem dúvida, a possuir mais problemas de saúde ${ }^{103}$ - que as empresas de planos de saúde tentem excluí-los de todas as formas possíveis ${ }^{104}$.

A consideração da hipervulnerabilidade do doente possui reflexos também na questão da publicidade. $\mathrm{O}$ doente, dependendo da doença, pode procurar desesperadamente por novos tratamentos para sua cura (assim como se nota no comportamento de Ivan Ilitch). Ocorre que há situações em que fornecedores, aproveitando-se de situações de desespero, oferecem produtos "milagrosos" que realizariam a pretensa cura de doenças

98 MARQUES, Cláudia Lima. Ibidem, p. 231.

99 Idem. Ibidem, p. 232.

100 Idem. Ibidem, p. 238.

101 Para a conceituação dos deveres anexos às obrigações ver SILVA, Clóvis V. do Couto. A obrigação como processo. Rio de Janeiro: FGV, 2006.

102 MARQUES, Cláudia Lima. Ibidem, p. 239-240. De outra forma, o mesmo ocorre com cláusulas que estabelecem prazos de internação em UTI, de acordo com a súmula 302 do STJ e também com a lei 9656/98 art. $12, \mathrm{II},{ }^{\mathrm{a}}$

Sobre o conceito de discriminação ver RIOS, Roger Raupp. Direito da Antidiscriminação: discriminação direta, indireta e ações afirmativas. Porto Alegre: Livraria do Advogado, 2008, p. 15: “designa a materialização, no plano concreto das relações sociais, de atitudes arbitrárias, comissivas ou omissivas, relacionadas ao preconceito, que produzem violação de direitos dos indivíduos e dos grupos".

103 Sendo assim um hipervulnerável por mais de uma razão.

104 SCHMITT, Cristiano Heineck. Ibidem: "Esta situação prejudica severamente aquele individuo que, durante boa parte de sua vida, contribuiu com mensalidades para com a empresa administradora de planos $e$ de seguros de saúde, e, ao alcançar uma faixa etária de maior risco, quando presumidamente utiliza-se com mais frequência dos serviços garantidos pelo seu contrato, é afastado ilicitamente da contratação". 
incuráveis. Em um caso paradigmático, o $\mathrm{STJ}^{105}$ reconheceu como enganosa a propaganda do chamado "cogumelo do sol" que prometia a cura do câncer. Foi apontado o abuso de direito do fornecedor e a hipervulnerabilidade dos doentes em tal condição "ludibriado por propaganda enganosa" ${ }^{\text {106 }}$. O acórdão cita também o art. 39, inc IV do CDC que define como prática abusiva aproveitar-se da fraqueza ou ignorância do consumidor em função, entre outras coisas, de sua saúde. ${ }^{107}$

De igual forma, a doutrina reconhece que, de maneira geral, a hipervulnerabilidade funciona como "um corolário positivo da proibição de discriminação"108. Cláudia Lima Marques indica que a proteção geral do hipervulnerável "tem potencial para ser um dos temas de maior destaque e conflitualidade na aplicação do CDC no futuro" ${ }^{\prime 109}$. O doente, em contratos cativos de longa duração - como os contratos envolvendo planos de saúde passa a contar com uma proteção especial contra tratamentos discriminatórios ${ }^{110}$. Também, reconhece-se que constituem dano moral in re ipsa, aquelas situações envolvendo a recusa indevida/injustificada ${ }^{111}$ em realizar tratamento médico bem como a demora injustificada no atendimento ${ }^{112}$.

Trata-se do reconhecimento de um "novo direito privado solidário"113. Consideramse os mais fracos como sujeitos que merecem uma proteção adicional ${ }^{114}$. Como se viu, o

105 SUPERIOR TRIBUNAL DE JUSTIÇA. $3^{\text {a }}$ Turma. REsp. 1.329.556/SP . Rel. Min. Ricardo Villas Bôas Cueva. J. em 25.11.2014.

106 Idem.

107 A problemática da publicidade abusiva atinge não apenas os doentes e idosos mas também as crianças, também vistas como sujeitos hipervulneráveis. Estas são comumente atingidas por publicidades subliminares na televisão, sendo incluídas "precocemente no mercado de consumo" (sendo conhecidos os casos em que se associam lanches com o oferecimento de brinquedos). As crianças são atingidas negativamente por propagandas de cigarro e bebidas o que enseja um tratamento especial deste tipo de publicidade. Sobre o tema ver BERTONCELLO, Káren Rick Danilevicz. Os efeitos da publicidade na 'vulnerabilidade agravada': como proteger as crianças consumidoras?. Revista de Direito do Consumidor. v. 90, p. 69-90, nov.-dez./2013, p. 74, 76 e 86.

108 MARQUES, Cláudia Lima. Ibidem, p. 363.

109 Idem. Ibidem, p. 370.

110 Idem. Ibidem, p. 377. Trata-se de ampliar a proteção por meio da imposição de deveres de cuidado "de cooperação e de informação, impondo uma boa-fé qualificada diante destes consumidores especiais..."

111 SUPERIOR TRIBUNAL DE JUSTIÇA.4 Turma. AgRg no AREsp 144.028/SP. Rel. Min. Marco Buzzi, j. em 03.04.2014.

112 SUPERIOR TRIBUNAL DE JUSTIÇA. 4 ${ }^{\mathrm{a}}$ Turma. REsp. 285.618/SP. Rel. Min. Luis Felipe Salomão, j. em 12.12.2008.

113 MARQUES, Cláudia Lima; MIRAGEM, Bruno. Ibidem, p. 25.

114 Segundo MARQUES, Cláudia Lima; MIRAGEM, Bruno. p. 109, os diferentes não devem ser discriminados, ao contrário, devem ser protegidos. Trata-se de uma "proteção especial ou qualificada", uma proteção que leve em conta as diferenças (p. 112). 
solidarismo dá uma nova tônica ao direito privado e amplia os deveres de cuidado e proteção dos fornecedores em relação aos consumidores hipervulneráveis. Cada vez mais o direito civil vai perdendo sua característica individualista, no esteira do movimento da "constitucionalização do direito privado" $"$. Trata-se de construir uma sociedade mais justa e solidária tendo no horizonte a consideração constante da dignidade da pessoa humana ${ }^{116}$ e a aplicação dos direitos fundamentais nas relações privadas, tudo isso "guiado pelos valores e a ordem constitucional ${ }^{, 117}$. Tais questões não deixam de estar ancoradas, por outro lado, no paradigma da socialidade que é encontrado no próprio Código Civil.

\section{Conclusões}

Com tudo o que se disse é possível afirmar que a obra de Tolstói permite apoiar a visão do doente como um hipervulnerável. Foi possível perceber, logo no início deste texto, a intensidade da narrativa que permite ao leitor colocar-se no lugar de Ivan Ilitch. $\mathrm{O}$ personagem central passa por um desespero e sofrimento agudos, com a dificuldade natural de aceitar sua doença e, logo depois, de aceitar a própria morte.

Sabe-se que uma das funções mais importantes das democracias modernas é a proteção das minorias ${ }^{118}$. Embora a doutrina indique que o consumidor doente é hipervulnerável por questões físicas, devem ser levantados também os aspectos psicológicos dessa vulnerabilidade ampliada. Ivan Ilitch sentia-se sozinho, contando com o desprezo da família e vendo, na figura de seu cuidador, talvez, sua única fonte de alívio e consolo. O personagem sofreu também, até o fim, em função de uma profunda depressão causada por sua condição física. Este aspecto da estória demonstra e expõe a necessidade da humanização do tratamento do doente, sobretudo, do doente terminal com a consideração do cuidado psicológico.

115 FACCHINI NETO, Eugênio. A constitucionalização do direito privado. Revista do Instituto de Direito Brasileiro. Ano 1, n. 1, p. 185-243, 2012.

116 Idem. Ibidem, p. 234.

117 MARQUES, Cláudia Lima; MIRAGEM, Bruno. p. 28. Tais questões não deixam de estar ancoradas, por outro lado, no paradigma da socialidade que é encontrado no próprio Código Civil, sobretudo, por meio da boa-fé objetiva e também da função social do contrato da propriedade e da posse. cf. MARTINSCOSTA, Judith; BRANCO, Gerson. Diretrizes teóricas do novo Código Civil Brasileiro. São Paulo: Saraiva, 2002, p. 64 e 144. Não se perca de vista que até a década de 70 o direito civil era marcadamente individualista e foi o projeto do Novo Código Civil de Reale que veio a trazer "nova luz sobre o problema", principalmente, por meio do princípio da boa-fé objetiva, cf. MARQUES, Cláudia Lima; MIRAGEM, Bruno. p. 116.

118 RIOS, Roger Raupp. Ibidem, p. 41. 
O grande desafio para o tratamento do doente hoje - visto como hipervulnerável - é o de como proporcionar um cuidado humanizado, dentro de uma perspetiva de proteção da dignidade da pessoa humana. Como criar cuidadores e profissionais "Guerássins"119 nos serviços de saúde é o grande desafio do Estado moderno ${ }^{120}$. O cuidado proporcionado pelo criado de Ivan Ilitch - que, diga-se de passagem, não possuía formação médica -, ao fim das contas, era o único que lhe causava verdadeiro conforto.

\section{Referências Bibliográficas}

AMARAL, Luiz Otávio de Oliveira. Teoria Geral do Direito do Consumidor. São Paulo: RT, 2010.

ARAÚJO, Fernando. Sorte Moral, Carácter e Tragédia Pessoal. Revista do Instituto de Direito Brasileiro. Ano 2, n. 1, p. 1-71, 2013

BARROSO, Luis Roberto. "Aqui, lá e em todo lugar": a dignidade humana no direito contemporâneo e no discrusos transnacional. In: BOGDANDY, Armin von; et all. Estudos avançados de Direitos Humanos: Democracia e Integração Jurídica: Emergência de um novo Direito Público. São Paulo: Elsevier, 2013.

BAUMAN, Zygmunt. Medo Líquido. Rio de Janeiro: Jorge Zahar, 2008.

- Vida para o consumo: a transformação das pessoas em mercadoria. Rio de Janeiro: Zahar, 2008

BERTONCELLO, Káren Rick Danilevicz. Os efeitos da publicidade na 'vulnerabilidade agravada': como proteger as crianças consumidoras?. Revista de Direito do Consumidor. v. 90, p. 69-90, nov.-dez./2013.

CALABRESI, Guido. The Costs os Accidents: A Legal and Economic Analysis. New Haven: Yale University Press, 1970, p. 17.

CHAVES, Antônio. Os direitos fundamentais da personalidade moral (à integridade psíquica, à segurança, à honra, ao nome, à imagem, à intimidade). Revista de Informação Legislativa. Ano 15, n. 58, p. 157-180, abr.-jun./1978.

COMTE-SPONVILLE, André. O capitalismo é moral? São Paulo: Martins Fontes, 2011.

119 CECILIO. Luis Carlos de Oliveira. Ibidem, p. 553: "Diante da deterioração das relações nos serviços de saúde, de práticas cada vez mais serializadas e impessoais de cuidado, do angustiante "diálogo de surdos" entre profissionais e pacientes, da baixíssima capacidade para dar respostas mais complexas e matizadas às necessidades de saúde portadas pelos usuários, a imagem comovedora do rico encontro Ilitch/Guerássim funcionaria como um fugidio e, cada vez mais distante, ideal a ser alcançado."

120 Como fazer, em um cenário de cuidado moderno, que os cuidadores tenham a mesma atenção que o criado Guerássim tem com Ivan Ilitch. Esta é interrogação central de CECILIO. Luis Carlos de Oliveira. Ibidem. 
DARWIN, Charles. A origem das espécies. 4ª ed. Belo Horizonte: Itatiaia, 2002.

FACCHINI NETO, Eugênio. A constitucionalização do direito privado. Revista do Instituto de Direito Brasileiro. Ano 1, n. 1, p. 185-243, 2012

FAUSTINO, Jean Carlos. A morte de Ivan Ilich: onde Tolstói, Dostoiéviski e Norbert Elias se encontram. Fragmentos, n. 38, p. 121-135, jan.-jun./2010.

FAVIER, Yann. Trad. AQUINI, Vinícius; BERTONCELLO, Káren Rick Danilevicz. A inalcançável definição de vulnerabilidade aplicada ao direito: abordagem francesa. Revista de Direito do Consumidor, n. 70, p. 15-24, jan.-fev./2013, p. 21.

GOFFMAN, Erving. Manicômios, prisões e conventos. São Paulo: Perspectiva, 1974.

HARENDT, Hannah. Eichmann em Jerusalém: Um relato sobre a banalidade do mal. São Paulo: Companhia das Letras, 1999

HEIDEGGER, Martin. Ser e Tempo: Parte II. 13ª ed.. Petrópolis: Vozes, 2005.

LLOSA, Mario Vargas. A civilização do espetáculo: Uma radiografia do nosso tempo e da nossa cultura. Rio de Janeiro: Objetiva, 2013.

MACHADO, Roberto et al. Danação da norma: medicina social e constituição da psiquiatria no Brasil. Rio de Janeiro: Graal, 1978.

MARQUES, Cláudia Lima. Contratos no Código de Defesa do Consumidor: O novo regime das relações contratuais. $7^{\mathrm{a}}$ ed. Rev. Atual. e amp. São Paulo: RT, 2014.

; MIRAGEM, Bruno. O novo direito privado e a proteção dos vulneráveis. São Paulo: RT, 2012.

MARTINS-COSTA, Judith; BRANCO, Gerson. Diretrizes teóricas do novo Código Civil Brasileiro. São Paulo: Saraiva, 2002.

MATEUS, Cibele Gralha. Direitos fundamentais sociais e relações privadas: o caso do direito à saúde na Constituição brasileira de 1988. Porto Alegre: Livraria do Advogado, 2008.

MIRAGEM, Bruno. Curso de Direito do Consumidor. 3a ed. São Paulo: RT, 2012.

MUSSE, Luciana Barbosa. Novos sujeitos de direito: as pessoas com transtorno mental na visão da bioética e do biodireito. São Paulo: Elsevier/Campus Jurídico, 2008.

PINTO, Louis. Pierre Bourdieau y la teoría del mundo social. Mexico DF: Siglo Veintiuno, 2002 ,

RIOS, Roger Raupp. Direito da Antidiscriminação: discriminação direta, indireta e ações afirmativas. Porto Alegre: Livraria do Advogado, 2008.

SARLET, Ingo Wolfgang. A eficácia dos direitos fundamentais: uma teoria geral dos direitos fundamentais na perspectiva constitucional. $10^{\mathrm{a}}$ ed. Porto Alegre: Livraria do Advogado, 2009.

SCHAEFER, Fernanda. A nova concepção do consentimento esclarecido. Revista do Instituto de Direito Brasileiro. Ano 1, n. 10, p. 6317-6354, 2012. 
SCHMITT, Cristiano Heineck. A "hipervulnerabilidade" do consumidor idoso. Revista de Direito do Consumidor. v. 70, p. 139-171, abr.-jun./2009, versão online.

SILVA, Clóvis V. do Couto. A obrigação como processo. Rio de Janeiro: FGV, 2006.

TOLSTÓI, Leon. A morte de Ivan Ilitch e Senhores e Servos. Rio de Janeiro: Nova Fronteira, 2013.

(Artigo submetido em 14/12/2014 e aceito em 30/12/2014) 